\title{
DEATH IN THE OPERATING ROOM
}

\author{
M. Minuck, M.D.*
}

The most obvious risks of an operation are those associated with anaesthesia.

-Editorial: The Lancet, Feb. 24/62, p. 414

ThE OPENING QUOTATION demonstrates the common tendency among surgeons, and even anaesthetists, to equate death in the operating room with death due to anaesthesia. Natof and Sadove, ${ }^{1}$ like many other authors, remark that "deaths associated with anaesthesia have increased in rather alarming and spectacular numbers," implying not only that a direct cause-and-effect relationship exists between these two, but also that this association has resulted in a significant increase in operating room fatalities. In order to test the validity of these statements, the case records of all the deaths that had occurred in the operating suite of the St. Boniface General Hospital from January 1949 to December 1964 were analysed with a view to determining the relative contributions made to operating room deaths by anaesthesia, surgery, pre-existing disease, and combinations of these factors.

The St. Boniface General Hospital is an acute general hospital affiliated as a teaching facility with the Manitoba Medical College. In 1956, the hospital expanded from 500 to 700 beds. The surgery that was performed covered the entire range and from 1958 included "open-heart" surgery. Over 96 per cent of the anaesthetic procedures in this review were performed in the operating room. The rest were done in the Department of Radiology and the "Emergency" Department where, since 1955, all bronchoscopies have been done. Ninety per cent of the cases were done with general anaesthesia, seven per cent with spinal analgesia, and three per cent with some other form of regional analgesia. Any case where the surgeon administered his own "local" analgesia without a member of the Department of Anaesthesia in attendance has been excluded.

The anaesthetics in the cases under review were administered by qualified physician-anaesthetists, by physicians training in anaesthesia, or by interns rotating through the anaesthetic service. The latter two groups discharged their anaesthetic duties under the supervision of a staff anaesthetist. The degree of supervision varied with the experience of the anaesthetist-in-training, the magnitude of the procedure, and the physical status of the patient. In addition to the "variable" individual supervision, one senior staff man is specifically designated as "float." Since 1955 the responsibilities of the "float" have included supervising of the postanaesthetic recovery room and being available for assistance should any serious complication or accident occur in the operating rooms. In order to be free for these duties he is not assigned any clinical cases.

For many years it has been our practice to discuss every death occurring within

-Assistant Professor of Surgery (Anaesthesia), University of Manitoba; Director, Department of Anaesthesia, St. Boniface General Hospital, St. Boniface, Manitoba. 
seven days of surgery and anaesthesia. The members of the department of anaesthesia discuss each case after the complete post mortem report becomes available; one of the pathologists regularly attends these meetings and, in addition, participates in the review done by the Department of Surgery. Before being submitted to analysis each case was reviewed by the author and changes were made when warranted by new knowledge gained from recent experience.

This paper is a review of all the factors associated with patients who died in the operating room, did not recover from the anaesthetic, or failed to recover from any serious complication which occurred during surgery and/or anaesthesia done between Janauary 1949 and December 1964. Table I contains a distribution

TABLE I

Classification of all Operating Room Deaths at the St. Boniface General Hospital from 1949 to 1964 Inclusive

\begin{tabular}{|c|c|c|}
\hline & Number & $\begin{array}{l}\text { Per cent of } \\
\text { total }\end{array}$ \\
\hline $\begin{array}{l}\text { 1. Deaths related to surgery* } \\
\text { solely surgical } \\
\text { surgery and pre-existing disease } \\
\text { surgery and anaesthesia (surgery major } \\
\text { factor) }\end{array}$ & $\begin{array}{rr}32 & 44 \\
7 & \\
5 & \end{array}$ & $\begin{array}{l}36.4 \\
26.4\end{array}$ \\
\hline $\begin{array}{l}\text { 2. Deaths related to anaesthesia } \\
\text { solely anaesthetic } \\
\text { anaesthesia and pre-existing disease } \\
\text { anaesthesia and surgery (anaesthesia major } \\
\text { factor) }\end{array}$ & $\begin{array}{rr}19 & 37 \\
10 & \\
8 & \end{array}$ & $\begin{array}{l}30.6 \\
15.4\end{array}$ \\
\hline $\begin{array}{l}\text { 3. Deaths related to pre-existing disease } \\
\text { 4. Deaths related to anaesthesia, surgery and } \\
\text { pre-existing disease }\end{array}$ & $\begin{array}{r}32 \\
8\end{array}$ & $\begin{array}{r}26.4 \\
6.6\end{array}$ \\
\hline Total & $121 \dagger$ & 100 \\
\hline
\end{tabular}

*See text for description of the major groups.

†Autopsies were done in $\mathbf{8 1}$ per cent of the deaths.

of the deaths according to the main factors implicated in the cause of the death. In division 1 are all the cases in which surgical factors were felt to be the major contributing factor. Thirty-six point four per cent fell into this category. This group is also subdivided into solely anaesthetic factors and contributing factors. Factors related to pre-existing disease are in division 3; it was felt that these patients would have died when they did from their presenting illness, whether surgery had been performed or not. The unassessable group, division 4, represents a potpourri of cases that could not be assigned to the other groups and were not readily assessable in spite of adequate information. The patients were doomed due to the severity of their basic illness or illnesses, but the times of their deaths were possibly influenced by the anaesthetic and surgical procedures. This group accounted for 6.6 per cent of the cases.

The contributing factors are broken down further in Table II. The factors concerning those deaths that occurred from 1949 to 1956, prior to the construction of the new hospital, have been placed in group $A$, and the remainder have been put into group $B$.

Tables III and IV contain a more detailed breakdown of the factors involved 


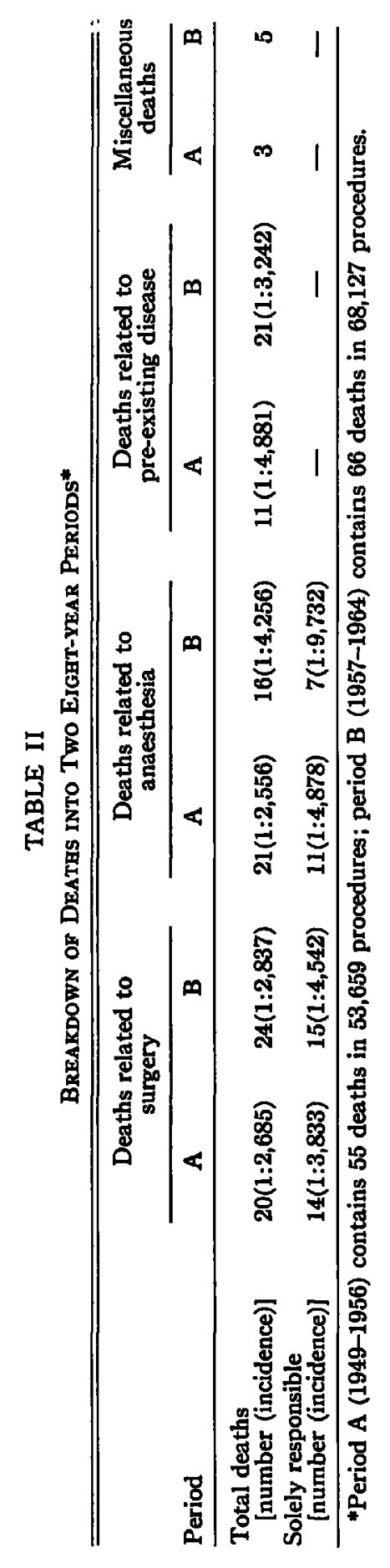


TABLE III

Factors That Contributed to Draths Related to Anaesthesta

\begin{tabular}{lr}
\hline \hline Improper premedication & 1 \\
Improper management of anaesthetic & \\
inadequate ventilation & 7 \\
myocardial depression & 11 \\
complication of regional technique & 6 \\
aspiration & 4 \\
technical failure to secure an airway & 2 \\
wrong gas & 2 \\
unclassifiable & 1 \\
Improper management of the immediate & \\
$\quad$ postoperative period (ventilation) & 3 \\
Total & 37 \\
\hline
\end{tabular}

TABLE IV

Causes of Deaths in the Group of Fatalities Due to Surgery

\begin{tabular}{lc}
\hline Uncontrollable haemorrhage & $24^{*}$ \\
Error in technique & 10 \\
Possibly non-preventable due to & 7 \\
$\begin{array}{l}\text { pre-existing disease } \\
\text { Air embolism }\end{array}$ & 1 \\
$\begin{array}{l}\text { Cerebral vascular accident (following a } \\
\text { craniotomy) }\end{array}$ & 1 \\
$\begin{array}{l}\text { Electrolyte imbalance (during an } \\
\text { open-heart procedure) }\end{array}$ & 1 \\
Total & 44 \\
\hline
\end{tabular}

-One patient was successfully resuscitated with external massage after her heart arrested following a brief haemorrhage, only to die at the end of the procedure. Death was found to be due to massive bleeding from a severely lacerated liver produced during the closedchest-compression.

TABLE V

Causes of Deaths in the Fatalities Due to Pre-existing Disease

\begin{tabular}{lr}
\hline \hline Severe myocardial depression & 6 \\
Peritonitis & 4 \\
Severe trauma & 4 \\
Ruptured aortic aneurysm & 4 \\
Abdominal haemorrhage & 3 \\
Inhalation of blood and/or gastric & 2 \\
contents (preoperative) & 2 \\
Pulmonary embolus during induction & 2 \\
Congenital heart disease & 2 \\
Intracerebral haemorrhage & 1 \\
Cerebral oedema & 1 \\
Meningitis & 1 \\
Stokes-Adams syndrome & 32 \\
Total & \\
\hline
\end{tabular}


TABLE VI

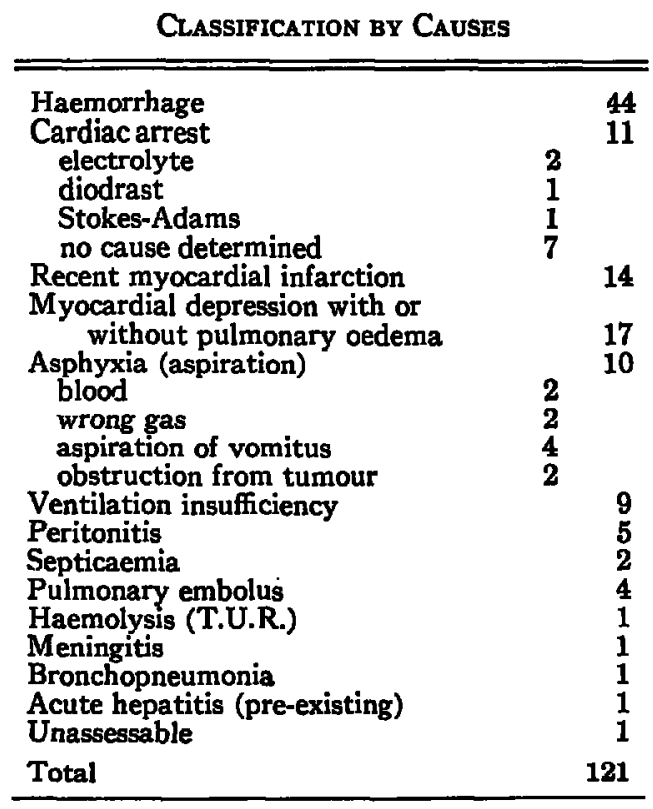

in the deaths related to anaesthesia and surgery respectively. The causes of death in the patients who died from pre-existing disease are listed in Table $\mathrm{V}$ and the causes of death in all the deaths are listed in Table VI.

\section{Discussion}

In order to include all deaths in which the conduct of the anaesthetic or the surgical technique might have been implicated, it was felt necessary to include, under the label of "operating room deaths," all those patients who died in the operating room, or failed to recover from the anaesthetic, or died later from the effects of some catastrophe occurring in the operating room.

There were 121 deaths in 121,786 anaesthetic procedures for a crude incidence of $1: 1,006$. Post mortem examinations were performed in 81 per cent of the cases. A review of the deaths did not support the popular belief expressed in the opening quotation. Table I reveals that 36.4 per cent of the deaths were related to surgery, 26.4 per cent died from their pre-existing disease, 6.6 per cent were unassessable, and only 30.6 per cent of the total number of deaths were related to anaesthesia. In fact, on further breakdown, only 15.6 per cent of the deaths were found to be due solely to the conduct of the anaesthetic.

The period under review was divided into two at a significant point in the development of the hospital. Our move into modern facilities was completed by 1956 and along with the large, well-lighted operating room, fully equipped with piped anaesthetic gases, suction and oxygen, we had, for the first time, a recovery room and a postsurgical intensive care unit. At the same time, the anaesthetic 
staff increased sufficiently to allow the implementation of the "float" principle which has been described above.

There was a rise in the deaths associated with pre-existing disease and little change in the deaths related to surgery (Table II). Modern advances in anaesthetic knowledge have increased patient safety, but curiously, there has not been a decrease in deaths not related to anaesthetics. This phenomenon can be explained by the increased number of poor-risk patients who are now offered lastditch surgery in the hope of cure or temporary rehabilitation. In addition, a significant contribution to operating room mortality has been the introduction of new techniques for patients with previously hopeless cardiac valvular disorders and for surgery done directly on diseased coronary arteries. Although the benefit of this type of surgery is indisputable, higher fatality rates are inevitable. This accounts in part for the increased number of deaths shown for the 1957-1964 period. For example, 18 out of the 66 operating room deaths during this period occurred in patients who were undergoing cardiac or major vascular (aortic aneurysm) surgery. There was a marked decrease in the deaths associated with anaesthesia in the 1957-1964 group when compared to the earlier group, the incidence falling from $1: 2556$ to 1:4256. In fact, the incidence of "pure" anaesthetic deaths during this latter period fell from 1:4878 to 1:9732. It is felt that this improvement was due to: (1) the availability of a "float" anaesthetist for immediate consultation and aid when difficulties arose during anaesthesia, (2) supervision of all anaesthetists-in-training, (3) organization of an efficient cardiac resuscitation routine in the operating room, (4) a heightened awareness of the dangers of anaesthesia in poor-risk patients, reflected in greater emphasis being placed on the preoperative assessment, (5) critical self-evaluation for the purpose of uncovering errors in technique and repetitive reappraisal of anaesthetic techniques and agents, and (6) the contribution to patient safety by the institution of a supervised postanaesthetic recovery room.

Aspiration continues as an important cause of operating room mortality (Table III) but increasing awareness of this complication, along with improved methods for its treatment, will continue to reduce the number of deaths that result from it. As a result of intensive efforts by many research anaesthesiologists, greater emphasis has been placed on problems of ventilation during and following surgery. Most of the ten deaths from this cause-seven during the procedure and three in the immediate postoperative period-occurred in the earlier period of the development of the hospital. The 11 instances of myocardial depression include several examples of "just give him a little bit of pentothal" for minor procedures in poor-risk patients. Uncontrollable bleeding was responsible for 24 of the 44 deaths related to surgery (Table IV). Some were errors in surgical technique such as the inadvertent opening of a large blood vessel, and the slipping-off of ligatures from a major blood vessel, but others were instances of prolonged bleeding associated with pulmonary, pancreatic and prostatic surgery. No clear-cut cause could be determined for the prolonged and uncontrollable bleeding but it was felt to be due to some ill-defined defect in clotting and coagulation mechanisms. A great deal has been written on this subject but it is beyond our scope to discuss it here. 
Comparison with the many published complications of operating room fatalities is difficult, for they vary so much in content. For example, procedures with a customarily low incidence of mortality such as vaginal deliveries, or minor procedures done with local infiltration of analgesic drugs are sometimes included. ${ }^{2-4}$ On the other hand, Boba ${ }^{5}$ included all instances of cardiac arrest, whether the patients survived or not, in his operating room mortality statistics. Regrettably, there is no uniform technique for the collection of data pertaining to operating room deaths, and the evaluation of these deaths is therefore seriously handicapped.

Province-wide mortality study committees have been organized over the past 15 years, but no attempt has been made to develop uniform techniques for the collection of the pertinent data and the evaluation of the contributing factors. The nation-wide organization of a common mechanism for collecting data on a large scale will permit the development of a method for measuring the care of patients undergoing surgery and anaesthesia. Any hospital medical staff, reviewing their record, will be able to use this yardstick in their efforts to improve patient care. Until this is done, the review of fatalities "associated with anaesthesia" will tend to remain merely popular exercises by anaesthesiologists and surgeons.

\section{SUMMARY}

An analysis has been made of the deaths which occurred during or shortly following anaesthesia at the St. Boniface General Hospital from 1949 to 1964 inclusive. Contributory factors due to anaesthesia, surgery, and pre-existing disease were considered. It was found that in almost 70 per cent of the fatalities, death was due to factors not related to anaesthetics. In fact, in only 15.6 per cent of the cases could it be determined that death was due purely to anaesthetic causes. It was also shown, on further breakdown into two eight-year periods, that a marked decrease took place in the number of deaths related to anaesthesia. The deaths dropped from an incidence of 1:4477 in the earlier period to 1:9728 in the later period. It was felt that this improvement was due mainly to the institution of a supervised postanaesthetic recovery room, the provision for a "float" anaesthetist, and repeated searching reviews of anaesthetic complications and operating room mortality.

Finally, a plea has been made for the development of a universal and uniform technique for the collection of data and the evaluation of all the factors associated with operating room mortality. This will lead to the compilation of more accurate statistics based on large-scale information that may be used by individual hospitals to assess their record.

\section{ACKNOWLEDGMENT}

I wish to acknowledge the invaluable help that I received from Dr. Max Cham in proofreading the manuscript. 


\section{RÉsumf́}

Nous avons fait une étude des décès survenus durant ou peu après l’anesthésie à l'Hôpital Général de St-Boniface de 1949 à 1964 inclusivement. On a tenu compte des facteurs dûs à l'anesthésie, à la chirurgie et aux maladies pré-existantes. On réalisé que dans presque 70 pour cent des fatalités, la mort était due à des facteurs indépendants de l’anesthésie. En effet, dans 15.6 pour cent seuloment des cas, on a pu conclure que la mort était due à des causes purement anesthésiques. On a démontré aussi, en comparant deux périodes de huit ans, qu'il y a eu une diminution marquée dans les cas de décès imputables à l'anesthésie. Dans la première série la fréquence était de 1 cas par 4477 malades, alors que dans la deuxième série elle n’était que de 1 car par 9728. Nous croyons que cette amélioration a été due surtout à l'établissement d'une salle de réveil surveillée, à la présence d'un anesthésiste constamment disponible, et à l'étude suivi des complications de l'anesthésie et de la mortalité à la salle d'opération.

Enfin, on s'est appliqué à développer une technique constante et uniforme pour receuillir les données et pour analyser tous les facteurs associés d̀ la mortalité dans la salle d'opération. Ceci amènera à compiler des statistiques plus précises basées sur des renseignements de grande portée; les différents hôpitaux peuvent se servir de ces données pour améliorer leurs records.

\section{REFERENCES}

1. Natof, H. E. \& Sadove, M. E. Cardiovascular Collapse in the Operating Rooms. Philadelphia: J. B. Lippincott Co. (1958), p. 2.

2. Hnvason, R. A.; Hornen, W. D.; \& Barnes, A. C. Mechanisms Involved in Anaesthetic Deaths. New York J. Med. 56: 230 (1956).

3. Clurton, B. S. \& Horren, W. I. T. Deaths Associated with Anaesthesia. Brit. J. Anaesth. 35: 250 (1963).

4. Jacoby, J. J.; Flory, F. A.; Zregleg, C. H.; \& Hamelneng, W. Anesth. \& Analg. $34: 347$ (1955).

5. BoвA, A. Death in the Operating Room. Springfield: Thomas (1965). 